\title{
The effect of elastic resistance band training with green coffee supplementation on novel hepatic steatosis biomarkers in obese women: A randomized controlled trial
}

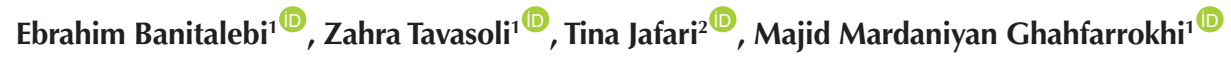 \\ 'Department of Sports Sciences, Shahrekord University, Shahrekord, Iran \\ ${ }^{2}$ Department of Biochemistry and Nutrition, Faculty of Medicine, Shahrekord University of Medical Sciences, Shahrekord, Iran
}

*Corresponding Author: Ebrahim Banitalebi, Department of Sports Sciences, Shahrekord University, Shahrekord, Iran, Email: banitalebi@sku.ac.ir

\begin{abstract}
Background and aims: The purpose of this study was to investigate the effect of eight weeks of resistance training (RT) using elastic bands together with green coffee supplement on novel hepatic steatosis biomarkers (hepatic steatosis index [HSI] and Framingham steatosis index [FSI]) in middle-aged obese women.

Materials and Methods: This study was a double-blind randomized clinical trial performed on the basis of the CONSORT Statement at Shahrekord University in Iran (summer 2018). For this purpose, 60 obese women aged 30-60 years with a body mass index (BMI) of $>30 \mathrm{~kg} /$ $\mathrm{m}^{2}$ were selected to participate in this study and then they were randomly assigned to one of the following four groups: green coffee (GC, $n=15)$, resistance training and placebo $(R T+P, n=15)$, green coffee and resistance training $(G C+R T, n=15)$, and placebo groups $(P, n=15)$.

Results: The results showed no significant differences in FSI $(P=0.822)$ and $\mathrm{HSI}(P=0.752)$ between four groups. However, there were significant increases in high density lipoprotein $(\mathrm{HDL})$ in the RT+P $(P=0.050)$ and $\mathrm{GC}+\mathrm{RT}$ groups $(P=0.032)$ and significant decreases in total cholesterol (TC) in the RT+P $(P=0.023), \mathrm{GC}+\mathrm{RT}(P=0.006)$, and GC groups $(P=0.041)$.

Conclusion: The reduction of hepatic steatosis biomarkers in these individuals may require a longer period of resistance workouts or other exercises.

Keywords: Elastic band resistance training, Green coffee, Hepatic steatosis biomarkers, Obesity
\end{abstract}

Received: 13 March 2020, Accepted: 1 June 2020, ePublished: 29 December 2020

\section{Introduction}

Due to lifestyle changes such as dietary habits and insufficient physical activities, the obesity rate is growing (500 million people are clinically obese) worldwide, especially in Iran (1). It has been reported that $50 \%$ of obese women suffer from nonalcoholic fatty liver disease (NAFLD) (2). Many researchers have also made efforts to identify and introduce a large number of novel biomarkers for predicting hepatic steatosis and monitoring responses to therapeutic strategies. Hepatic steatosis index (HSI) and Framingham steatosis index (FSI) are considered as useful tools, which have been developed in recent years for primary prevention of hepatic disease at individual and clinical levels (3-5).

The major intervention offered for fatty liver in obese people is lifestyle changes including weight loss, medicinal foods, as well as regular exercise (6). Typically, poor adherence to aerobic exercises may be problematic in obese women due to a need for high aerobic capacity and early exhaustion (7). Therefore, scarce data have recently shown that the use of resistance exercise (RT) modality has become more popular in obese adults to improve hepatic disorders $(8,9)$. The liver-related benefits of RT for obese women include reduction of visceral adipose tissue and obesity indices (10). Additionally, lower cardiorespiratory demand is required by resistance exercises that are associated with similar metabolic benefits $(9,11)$.

Several studies have reported that the consumption of green coffee (GC), as a rich source of bioactive chlorogenic acid (CGA), plays a protective role against the development of hepatic risk factors $(12,13)$, obesity (14), and increased hepatic triglyceride (TG) levels (15). Recently, exercise scientists have suggested the complementary role of exercise and herbal medicine $(16,17)$. It has also been reported that physical training may accelerate certain adaptations when it is combined with herbal medicines that may not be achieved in response to pharmaceuticals alone $(18,19)$. To the best of our knowledge, there has yet been no published study on the impact of GC consumption and elastic RT program on novel noninvasive indices for hepatic steatosis in obese women. Therefore, the purpose of this study was to compare the effects of GC consumption and elastic

(C) 2020 The Author(s); Published by Shahrekord University of Medical Sciences. This is an open-access article distributed under the terms of the Creative Commons Attribution License (http://creativecommons.org/licenses/by/4.0), which permits unrestricted use, distribution, and reproduction in any medium, provided the original work is properly cited. 
RT program on novel noninvasive biomarkers for hepatic steatosis (HSI and FSI) in obese women.

\section{Materials and Methods}

This study was a double-blind randomized clinical trial performed on the basis of the CONSORT Statement at Shahrekord University, Iran (20). The protocol was registered in the Iranian Registry of Clinical Trials (identifier: IRCT2017090419995N9). Information about the study design, objectives, procedures, as well as benefits and potential risks were presented at the beginning of the study and then the informed consent was obtained from each participant. The flow diagram of the study design was presented in Figure 1.

Participants were recruited through brochures and newspaper announcements (Shahrekord, Iran) according to the following criteria. The participants were sedentary, 30-60 years old, non-menopause, and class I/II obese $\left(39.9<\mathrm{BMI}>30 \mathrm{~kg} / \mathrm{m}^{2}\right)$. Sedentary was defined as no more than 20-minute exercise per week over the past 6 months. The exclusion criteria were as follows: having thyroid disorder, being nursing mothers, following regular exercise training and diet, using weight loss drugs or phytochemicals, having blood pressure $\geq 160 / 100 \mathrm{~mm}$ $\mathrm{Hg}$, fasting triglyceride $\geq 500 \mathrm{mg} / \mathrm{dL}$, having a history of cardiovascular diseases, cancer, hepatic diseases, metabolic syndromes, and hormonal disorders, using hormone therapy, alcohol abuse, using steatogenic drugs, as well as being pregnant, using supplements on a regular basis or participating in other clinical trials over the past 3 months (3). The sample size was calculated considering: (a) two-way ANOVA, (b) 4 groups, (c) type I error=5\%, (d) type II error $=20 \%$, (e) power of statistical test $=80 \%$, and (f) effect size $=0.20$. The sample size in this study was measured using $\mathrm{G}^{*}$ Power 3 (21). The effect size of GC was also estimated to be 5 IU/L for serum ALT levels (3). Using a statistical power of 0.80 , an effect size of 1.08 , and an alpha value of 0.05 , a total sample size of 80 individuals (20 per group) was determined considering the potential dropouts of $15 \%$.

The patients were randomized by block allocation with a block size of 6 by a research assistant who was not involved in this research using a computer-generated random number sequence. Participants were stratified according to two cut-offs for stratifications of age (30-50 or 51-60 years), BMI (25-35 or $\left.36-48 \mathrm{~kg} / \mathrm{m}^{2}\right)$, and HbA1c $(6.5-$ $8.5 \%$ or $\geq 8.6 \%)$.

After baseline assessments, a total of 60 eligible subjects (39.9<BMI> $30 \mathrm{~kg} / \mathrm{m}^{2}$ ) were randomized by block allocation with a block size of 8 by a research assistant who was not involved in this research to one of the four groups [(resistance training and placebo group (RT+P, $\mathrm{n}=15$ ), green coffee supplement (GC, $\mathrm{n}=15)$, green coffee supplement and resistance training (GC+RT, $\mathrm{n}=15)$,

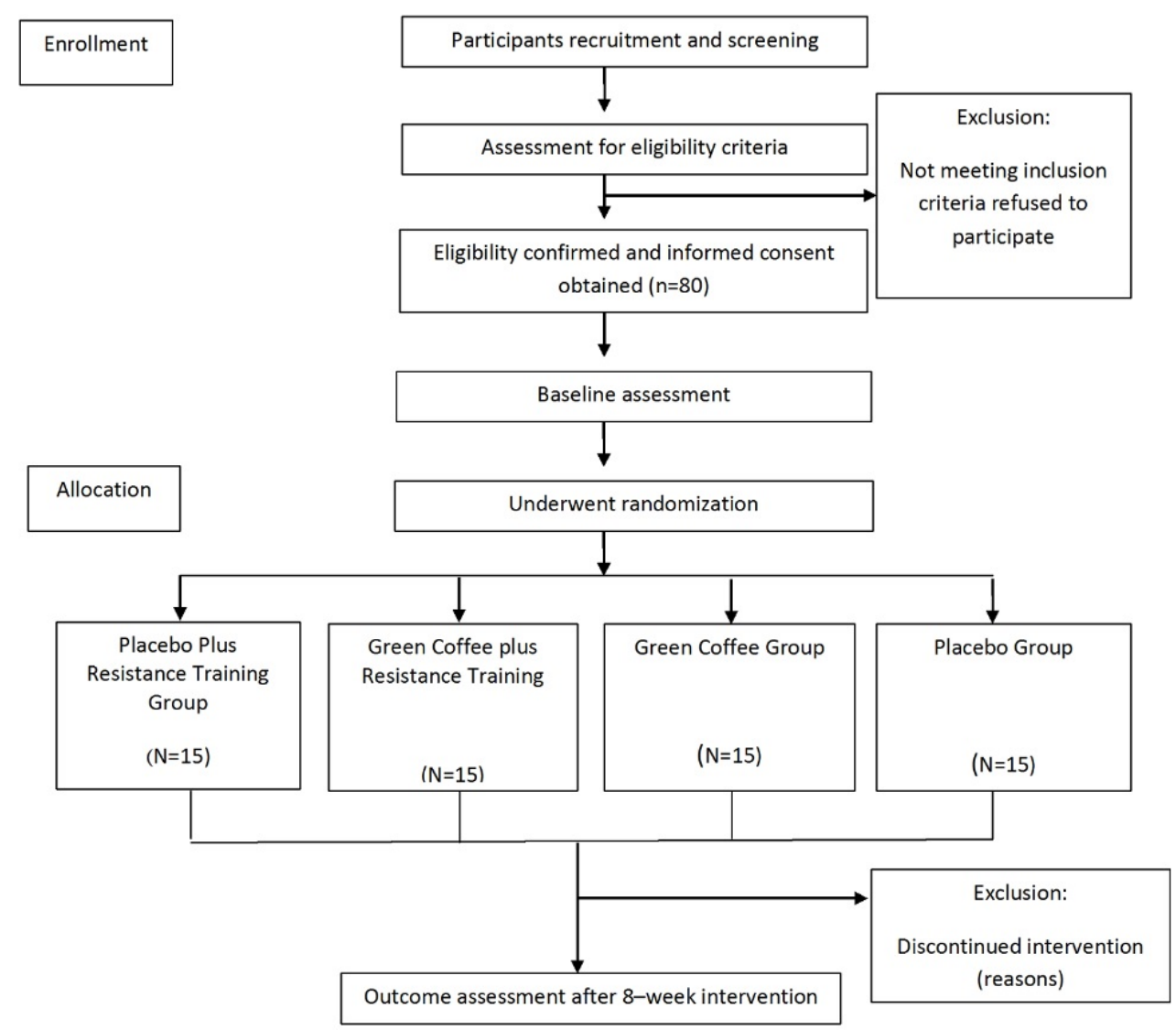

Figure 1. CONSORT flow diagram . 
and placebo group $(\mathrm{P}, \mathrm{n}=15)]$ in a ratio of 1:1:1:1 using a computer-generated random number sequence. The allocation sequence was concealed in sealed opaque envelopes, which were not opened until the baseline assessment was completed. The participants were also blind to group allocation and underwent an 8-week intervention. Two subjects from RT+P group, two subjects from the $\mathrm{P}$ group, one subject from GC+RT group, and one subject from the GC group withdrew from the trial following randomization. Moreover, dropout rates were calculated as the percentage of the participants failed to continue their participation for 8 weeks.

Commercially prepared GC bean capsules were used in this study. Additional information is represented in supplementary data. Details of the exercise training program are illustrated in the supplementary file. Briefly, RT was done using Thera-band products (Hygenic Co., Akron, $\mathrm{OH}$ ). The colors of the band include yellow, red, green, and blue. During the 8 weeks of resistance training, all subjects had three sessions per week and were monitored by a licensed senior exercise physiologist who was blind to the study group members. Additional information is represented in supplementary data file and supplementary Tables 1 and 2.

\section{Calculation of Novel Hepatic Steatosis Indices}

$\mathrm{HSI}=8(\mathrm{ALT} / \mathrm{AST})$ ratio+BMI+2 $(4,22)$.

FSI $=-7.981+0.011 \times$ age $($ years $)-0.173 \times$ BMI $\left(\mathrm{kg} / \mathrm{m}^{2}\right)+$ $0.007 \times$ triglycerides $(\mathrm{mg} / \mathrm{dL})+1.1 \times$ ALT/AST ratio $\geq 1.33$ (yes=1, no=0) (23).

To compare the pretest and posttest scores in each group, a dependent $t$ test was used and all the values were presented as mean \pm standard deviation. KolmogorovSmirnov test was also performed for testing normality of distribution. One-way ANOVA was used for baseline comparisons between four groups. Two-way ANOVA (Group * Time) was conducted to compare the changes in experimental and control groups after eight weeks. When a significant F-value was achieved, the Bonferroni post hoc test was used to investigate the differences between the groups. Significance level $(P)$ was considered to be $<0.05$.

\section{Results}

The participants' baseline characteristics were shown in Table 1. None of the subjects experienced an adverse event as a result of participation in this research which might need medical treatment or any clinical findings required for medical referral. Participants of the present study had satisfactory adherence to the interventions. The dropout

Table 1. Descriptive characteristics of $P+R, G C+R, G C$, and $P$ groups at baseline level

\begin{tabular}{|c|c|c|c|c|c|}
\hline Variable & $P+R$ group $(n=15)$ & $\begin{array}{c}\text { GC+R group } \\
(n=15)\end{array}$ & $\begin{array}{c}\text { GC group } \\
(n=15)\end{array}$ & $\begin{array}{c}\text { P group } \\
(n=15)\end{array}$ & $\begin{array}{c}P \text {-value } \\
\text { (between groups) }\end{array}$ \\
\hline Age $(y)$ & $37.46 \pm 6.70$ & $35.15 \pm 5.29$ & $39.85 \pm 6.23$ & $39.67 \pm 5.59$ & 0.171 \\
\hline Height $(\mathrm{cm})$ & $157.77 \pm 6.26$ & $158.79 \pm 7.06$ & $159 \pm 5.34$ & $161.15 \pm 4.07$ & 0.511 \\
\hline Body mass (kg) & $82.55 \pm 12.72$ & $86 \pm 10.08$ & $86.03 \pm 8.46$ & $85.72 \pm 7.26$ & 0.113 \\
\hline $\mathrm{WC}(\mathrm{cm})$ & $99.69 \pm 7.80$ & $100.54 \pm 7.58$ & $104 \pm 6.76$ & $102.42 \pm 7.07$ & 0.424 \\
\hline $\mathrm{BMI}\left(\mathrm{kg} / \mathrm{m}^{2}\right)$ & $33.12 \pm 2.52$ & $34.1 \pm 3.31$ & $34.07 \pm 3.43$ & $33.01 \pm 2.59$ & 0.092 \\
\hline Body fat (\%) & $45.59 \pm 2.97$ & $46.16 \pm 2.37$ & $44.43 \pm 3.64$ & $43.93 \pm 2.66$ & 0.052 \\
\hline WHR & $0.979 \pm 0.12$ & $0.96 \pm 0.05$ & $0.89 \pm 0.05$ & $0.88 \pm 0.06$ & 0.064 \\
\hline Daily calorie (kcal/d) & $1816.5 \pm 92.02$ & $1868.4 \pm 74.77$ & $1890.4 \pm 108.9$ & $1902.7 \pm 1103.9$ & 0.642 \\
\hline Carbohydrate \% & $53.92 \pm 4.39$ & $57.92 \pm 5.76$ & $56.5 \pm 7.79$ & $55.53 \pm 4.43$ & 0.391 \\
\hline Fat $\%$ & $29.92 \pm 5.02$ & $28.14 \pm 5.47$ & $31.76 \pm 7.53$ & $29.38 \pm 4.72$ & 0.708 \\
\hline Protein \% & $16.15 \pm 5$ & $13.93 \pm 4.25$ & $11.46 \pm 4.49$ & $15.08 \pm 5.31$ & 0.396 \\
\hline $\mathrm{HDL}(\mathrm{mg} / \mathrm{dL})$ & $48.27 \pm 4$ & $48.44 \pm 6.95$ & $42.91 \pm 4.76$ & $47.17 \pm 7.96$ & 0.072 \\
\hline $\mathrm{LDL}(\mathrm{mg} / \mathrm{dL})$ & $101.37 \pm 24.83$ & $87.86 \pm 17.74$ & $91.17 \pm 23.15$ & $99.47 \pm 28.79$ & 0.401 \\
\hline TG (mg/dL) & $159.46 \pm 43.59$ & $161.5 \pm 35.34$ & $147.36 \pm 53.58$ & $151.54 \pm 38.6$ & 0.809 \\
\hline $\mathrm{TC}(\mathrm{mg} / \mathrm{dL})$ & $188.61 \pm 35.33$ & $172 \pm 27.39$ & $166.64 \pm 26.71$ & $183.38 \pm 26.41$ & 0.196 \\
\hline ALT (IU/L) & $15.31 \pm 2.81$ & $15.36 \pm 1.55$ & $17.14 \pm 2.48$ & $14.63 \pm 1.99$ & $0.034^{*}$ \\
\hline AST (IU/L) & $15.61 \pm 3.99$ & $16.29 \pm 4.23$ & $16.64 \pm 4.63$ & $15.58 \pm 3.87$ & 0.890 \\
\hline GGT (IU/L) & $14.75 \pm 5.5$ & $14.29 \pm 6.23$ & $14.49 \pm 4.19$ & $16.51 \pm 4.12$ & 0.667 \\
\hline $\mathrm{FBG}(\mathrm{mg} / \mathrm{dL})$ & $94.61 \pm 8.12$ & $94.36 \pm 10.67$ & $94.07 \pm 7.39$ & $91.46 \pm 10.28$ & 0.477 \\
\hline Insulin (IU/L) & $15.69 \pm 2.51$ & $16.74 \pm 1.93$ & $16.35 \pm 3.08$ & $15.17 \pm 3.02$ & 0.163 \\
\hline FSI & $-0.78 \pm 0.76$ & $-0.48 \pm 0.79$ & $-0.52 \pm 0.87$ & $-0.90 \pm 0.49$ & 0.401 \\
\hline $\mathrm{HSI}$ & $73.69 \pm 7.25$ & $76.42 \pm 6.21$ & $76.45 \pm 6.52$ & $74.11 \pm 6.91$ & 0.700 \\
\hline
\end{tabular}

Abbreviations: RT, Resistance training; GC, Green coffee; P, Placebo; ALT, Alanine aminotransferases; AST, Aspartate aminotransferases; GGT, Gamma glutamyl transferase; HSI, Hepatic steatosis index; FSI, Framingham steatosis index; FBG, Fasting blood glucose; BMI, Body mass index; HDL, High density lipoprotein; TG, Triglyceride; WC, Waist circumference; MAP, Mean arterial pressure; WHR, Waist-to-hip ratio; TC, Total cholesterol.

One-way ANOVA was used for baseline comparisons in four groups. * significant differences between groups at baseline level. 
Table 2. Comparison of Body Composition between Groups after 8 Weeks of Intervention

\begin{tabular}{|c|c|c|c|c|c|c|}
\hline Variable & Time & $\begin{array}{l}\text { P+RT group } \\
\quad(n=15)\end{array}$ & $\begin{array}{c}\text { GC+RT group } \\
\quad(n=15)\end{array}$ & $\begin{array}{l}\text { GC group } \\
(n=15)\end{array}$ & $\begin{array}{l}\text { P group } \\
(n=15)\end{array}$ & $\begin{array}{c}P \text {-value } \\
\text { (differences between groups) }\end{array}$ \\
\hline \multirow{3}{*}{ Body mass (kg) } & Pre-test & $82.55 \pm 12.72$ & $86 \pm 10.08$ & $86.03 \pm 8.46$ & $85.72 \pm 7.26$ & \multirow{3}{*}{0.730} \\
\hline & Post-test & $79.73 \pm 11.78$ & $83.09 \pm 10.44$ & $82.47 \pm 9.01$ & $84.18 \pm 6.49$ & \\
\hline & $P$ value (within groups) & 0.001 & 0.001 & 0.002 & 0.141 & \\
\hline \multirow{3}{*}{ WC $(\mathrm{cm})$} & Pre-test & $99.69 \pm 7.80$ & $100.54 \pm 7.58$ & $104 \pm 6.76$ & $102.42 \pm 7.07$ & \multirow{3}{*}{0.385} \\
\hline & Post-test & $97.12 \pm 7.11$ & $98 \pm 7.47$ & $100.88 \pm 6.06$ & $101.37 \pm 7.26$ & \\
\hline & $P$ value (within groups) & 0.001 & 0.001 & 0.001 & 0.314 & \\
\hline \multirow{3}{*}{$\mathrm{BMI}\left(\mathrm{kg} / \mathrm{m}^{2}\right)$} & Pre-test & $33.12 \pm 2.52$ & $34.1 \pm 3.31$ & $34.07 \pm 3.43$ & $33.01 \pm 2.59$ & \multirow{3}{*}{0.892} \\
\hline & Post-test & $32 \pm 4.30$ & $32.91 \pm 3.01$ & $32.66 \pm 3.57$ & $32.51 \pm 3.46$ & \\
\hline & $P$ value (within groups) & 0.001 & 0.001 & 0.003 & 0.088 & \\
\hline \multirow{3}{*}{ Body fat $(\%)$} & Pre-test & $45.59 \pm 2.97$ & $46.16 \pm 2.37$ & $44.43 \pm 3.64$ & $43.93 \pm 2.66$ & \multirow{3}{*}{0.398} \\
\hline & Post-test & $43.27 \pm 3.24$ & $43.93 \pm 2.22$ & $42.37 \pm 3.58$ & $43.20 \pm 2.13$ & \\
\hline & $P$ value (within groups) & 0.001 & 0.001 & 0.001 & 0.129 & \\
\hline \multirow{3}{*}{ WHR } & Pre-test & $0.979 \pm 0.12$ & $0.96 \pm 0.05$ & $0.89 \pm 0.05$ & $0.881 \pm 0.06$ & \multirow{3}{*}{0.054} \\
\hline & Post-test & $0.926 \pm 0.09$ & $0.948 \pm 0.05$ & $0.888 \pm 0.12$ & $0.88 \pm 0.06$ & \\
\hline & $P$ value (within groups) & 0.015 & 0.192 & 0.786 & 0.791 & \\
\hline \multirow{3}{*}{ Daily calorie $(\mathrm{kcal} / \mathrm{d})$} & Pre-test & $1816.5 \pm 92.02$ & $1868.4 \pm 74.77$ & $1890.4 \pm 108.9$ & $1902.7 \pm 103.9$ & \multirow{3}{*}{0.117} \\
\hline & Post-test & $1629.5 \pm 54.51$ & $1699.1 \pm 66.50$ & $1702.2 \pm 85.16$ & $1949 \pm 90.92$ & \\
\hline & $P$ value (within groups) & 0.032 & 0.002 & 0.119 & 0.470 & \\
\hline \multirow{3}{*}{ Carbohydrate \% } & Pre-test & $53.92 \pm 4.39$ & $57.92 \pm 5.76$ & $56.5 \pm 7.79$ & $55.53 \pm 4.43$ & \multirow{3}{*}{0.808} \\
\hline & Post-test & $53.84 \pm 6.72$ & $49.64 \pm 7.57$ & $52.36 \pm 10.03$ & $58.38 \pm 5.78$ & \\
\hline & $P$ value (within groups) & 0.966 & 0.006 & 0.255 & 0.085 & \\
\hline \multirow{3}{*}{ Fat $\%$} & Pre-test & $29.92 \pm 5.02$ & $28.14 \pm 5.47$ & $31.76 \pm 7.53$ & $29.38 \pm 4.72$ & \multirow{3}{*}{0.643} \\
\hline & Post-test & $27 \pm 5.43$ & $30.09 \pm 4.49$ & $32.57 \pm 9.12$ & $27.31 \pm 4.64$ & \\
\hline & $P$ value (within groups) & 0.153 & 0.293 & 0.756 & 0.294 & \\
\hline \multirow{3}{*}{ Protein \% } & Pre-test & $16.15 \pm 5$ & $13.93 \pm 4.25$ & $11.46 \pm 4.49$ & $15.08 \pm 5.31$ & \multirow{3}{*}{0.532} \\
\hline & Post-test & $19.92 \pm 4.54$ & $20.36 \pm 5.81$ & $15.38 \pm 4.01$ & $14.23 \pm 4.25$ & \\
\hline & $P$ value (within groups) & 0.095 & 0.001 & 0.064 & 0.702 & \\
\hline
\end{tabular}

Abbreviations: RT, Resistance training, GC, Green coffee; P, placebo; BMI, Body mass index; HDL, High density lipoprotein; TG, Triglyceride; WC, Waist circumference; MAP, Mean arterial pressure; WHR, Waist-to-hip ratio;

A paired sample $t$ test was used to conduct intra-group comparisons (pre-post changes). A two-way ANOVA test was also used to investigate differences between groups. Bonferroni correction was also applied as post-hoc test.

rate was only $10 \%$, which was less than conservative anticipation in this study. No significant differences were observed in dropout rates between the four groups.

Table 2 shows the body composition of the participants in the experimental groups. In $\mathrm{RT}+\mathrm{P}$ group, there were significant decreases in body mass $(P=0.001)$, waist circumference (WC) $\quad(P=0.001), \quad$ BMI $\quad(P=0.001)$, body fat percentage $(P=0.001)$, waist-to-hip ratio (WHR) $(P=0.015)$, and mean daily calorie $(P=0.032)$. Additionally, in GC+RT group, there were significant decreases in body mass $(P=0.001)$, WC $(P=0.001)$, BMI $(P=0.001)$, body fat percentage $(P=0.001)$, mean daily calorie $(P=0.002)$, carbohydrate $(P=0.006)$, and protein $(P=0.001)$. A significant decrease in body mass $(P=0.002)$, WC $(P=0.001)$, BMI $(P=0.003)$, and body fat percentage $(P=0.001)$ was observed in the GC group. The placebo group also showed no changes in all the body composition variables $(P \geq 0.05)$. There were no significant differences between the four groups in all body composition and diet characteristics variables $(P \geq 0.05)$.

In the $\mathrm{RT}+\mathrm{P}$ group, high density lipoprotein (HDL) $(P=0.007)$, TG $(P=0.012)$, GGT $(P=0.050)$, glucose $(P=0.001)$, FSI $(P=0.034)$, and HSI $(P=0.014)$ significantly decreased. In the GC+RT group, there was a significant decrease in HDL $(P=0.010)$, TG $(P=0.003)$, aspartate aminotransferases (AST) $(P=0.007)$, glucose $(P=0.001)$, FSI $(P=0.021)$, and HSI $(P=0.027)$. Moreover, in the GC group, HSI $(P=0.023)$ significantly declined. There were no significant differences in the $\mathrm{P}$ group $(P \geq 0.05)$ (Table 3).

Furthermore, the results of two-way ANOVA showed no significant differences in novel hepatic steatosis indices (FSI, and HSI) between the four groups $(P \geq 0.05)$. However, there were significant differences in $\mathrm{HDL}$ $(P=0.020)$ and total cholesterol (TC) $(P=0.045)$. After post-hoc comparisons, it was found that $\mathrm{HDL}$ in the $\mathrm{RT}+\mathrm{P}$ 
Table 3. Comparison of Changes in Biochemical Biomarkers between Groups after 8 Weeks of Intervention

\begin{tabular}{|c|c|c|c|c|c|c|}
\hline Variable & Time & $\begin{array}{l}P+\mathbf{R T} \text { group } \\
\quad(\mathrm{n}=15)\end{array}$ & $\begin{array}{c}\text { GC+RT group } \\
(n=15)\end{array}$ & $\begin{array}{l}\text { GC group } \\
(n=15)\end{array}$ & $\begin{array}{l}\text { P group } \\
(n=15)\end{array}$ & $\begin{array}{c}P \text {-value } \\
\text { (differences between groups) }\end{array}$ \\
\hline \multirow{3}{*}{$\mathrm{HDL}(\mathrm{mg} / \mathrm{dL})$} & Pre-test & $48.27 \pm 4$ & $48.44 \pm 6.95$ & $42.91 \pm 4.76$ & $47.17 \pm 7.96$ & \multirow{3}{*}{$0.020^{*}$} \\
\hline & Post-test & $51.06 \pm 3.92$ & $51.41 \pm 7.27$ & $43.91 \pm 5.81$ & $47.40 \pm 7.92$ & \\
\hline & $P$ value (within groups) & 0.007 & 0.010 & 0.356 & 0.885 & \\
\hline \multirow{3}{*}{$\mathrm{LDL}(\mathrm{mg} / \mathrm{dL})$} & Pre-test & $101.37 \pm 24.83$ & $87.86 \pm 17.74$ & $91.17 \pm 23.15$ & $99.47 \pm 28.79$ & \multirow{3}{*}{0.206} \\
\hline & Post-test & $88.63 \pm 31.16$ & $78.06 \pm 22.29$ & $85.29 \pm 21.38$ & $103.05 \pm 28.93$ & \\
\hline & $P$ value (within groups) & 0.026 & 0.074 & 0.182 & 0.540 & \\
\hline \multirow{3}{*}{ TG (mg/dL) } & Pre-test & $159.46 \pm 43.59$ & $161.5 \pm 35.34$ & $147.36 \pm 53.58$ & $151.54 \pm 38.6$ & \multirow{3}{*}{0.908} \\
\hline & Post-test & $50.46 \pm 40.35$ & $148.29 \pm 34.45$ & $142.23 \pm 51.71$ & $150.77 \pm 39.81$ & \\
\hline & $P$ value (within groups) & 0.012 & 0.003 & 0.071 & 0.942 & \\
\hline \multirow{3}{*}{$\mathrm{TC}(\mathrm{mg} / \mathrm{dL})$} & Pre-test & $188.61 \pm 35.33$ & $172 \pm 27.39$ & $166.64 \pm 26.71$ & $183.38 \pm 26.41$ & \multirow{3}{*}{$0.045^{*}$} \\
\hline & Post-test & $180.06 \pm 35.02$ & $160.01 \pm 24.08$ & $161.29 \pm 25.06$ & $192.22 \pm 18.39$ & \\
\hline & $P$ value (within groups) & 0.088 & 0.015 & 0.243 & 0.020 & \\
\hline \multirow{3}{*}{ ALT (IU/L) } & Pre-test & $15.31 \pm 2.81$ & $15.36 \pm 1.55$ & $17.14 \pm 2.48$ & $14.63 \pm 1.99$ & \multirow{3}{*}{0.061} \\
\hline & Post-test & $14.23 \pm 3$ & $14.50 \pm 2.77$ & $16.57 \pm 3.11$ & $14.95 \pm 2.10$ & \\
\hline & $P$ value (within groups) & 0.073 & 0.152 & 0.241 & 0.559 & \\
\hline \multirow{3}{*}{ AST (IU/L) } & Pre-test & $15.61 \pm 3.99$ & $16.29 \pm 4.23$ & $16.64 \pm 4.63$ & $15.58 \pm 3.87$ & \multirow{3}{*}{0.704} \\
\hline & Post-test & $14.54 \pm 2.99$ & $14 \pm 3.46$ & $16.36 \pm 2.82$ & $15.77 \pm 4.02$ & \\
\hline & $P$ value (within groups) & 0.084 & 0.007 & 0.725 & 0.806 & \\
\hline \multirow{3}{*}{ GGT (IU/L) } & Pre-test & $14.75 \pm 5.5$ & $14.29 \pm 6.23$ & $14.49 \pm 4.19$ & $16.51 \pm 4.12$ & \multirow{3}{*}{0.184} \\
\hline & Post-test & $12.3 \pm 5.21$ & $14.1 \pm 4.82$ & $14.23 \pm 3.22$ & $17.35 \pm 4.93$ & \\
\hline & $P$ value (within groups) & 0.050 & 0.878 & 0.852 & 0.608 & \\
\hline \multirow{3}{*}{$\mathrm{FBG}(\mathrm{mg} / \mathrm{dL})$} & Pre-test & $94.61 \pm 8.12$ & $94.36 \pm 10.67$ & $94.07 \pm 7.39$ & $91.46 \pm 10.28$ & \multirow{3}{*}{0.058} \\
\hline & Post-test & $89.08 \pm 9.70$ & $84.5 \pm 11.02$ & $91.79 \pm 8.50$ & $99.92 \pm 20.12$ & \\
\hline & $P$ value (within groups) & 0.001 & 0.001 & 0.071 & 0.053 & \\
\hline \multirow{3}{*}{ Insulin (IU/L) } & Pre-test & $15.69 \pm 2.51$ & $16.74 \pm 1.93$ & $16.35 \pm 3.08$ & $15.17 \pm 3.02$ & \multirow{3}{*}{0.166} \\
\hline & Post-test & $14.62 \pm 2.64$ & $15.39 \pm 2.12$ & $15.63 \pm 2.71$ & $14.99 \pm 2.58$ & \\
\hline & $P$ value (within groups) & 0.030 & 0.001 & 0.118 & 0.774 & \\
\hline \multirow{3}{*}{$\mathrm{FSI}$} & Pre-test & $-0.78 \pm 0.76$ & $-0.48 \pm 0.79$ & $-0.52 \pm 0.87$ & $-0.90 \pm 0.49$ & \multirow{3}{*}{0.822} \\
\hline & Post-test & $-1.04 \pm 0.7696$ & $-0.85 \pm 0.63$ & $-0.80 \pm 0.95$ & $-1.01 \pm 0.53$ & \\
\hline & $P$ value (within groups) & 0.034 & 0.021 & 0.053 & 0.075 & \\
\hline \multirow{3}{*}{$\mathrm{HSI}$} & Pre-test & $73.69 \pm 7.25$ & $76.42 \pm 6.21$ & $76.45 \pm 6.52$ & $74.11 \pm 6.91$ & \multirow{3}{*}{0.752} \\
\hline & Post-test & $71.55 \pm 6.66$ & $74.09 \pm 5.57$ & $73.69 \pm 6.78$ & $73.24 \pm 7.23$ & \\
\hline & $P$ value (within groups) & 0.014 & 0.027 & 0.023 & 0.398 & \\
\hline
\end{tabular}

Abbreviations: RT, Resistance training; GC, Green coffee; P, placebo; ALT, Alanine aminotransferases; AST, Aspartate aminotransferases; GGT, Gamma glutamyl transferase; HIS, Hepatic steatosis index; FSI, Framingham steatosis index; FBG, Fasting blood glucose; BMI, Body mass index; HDL, High density lipoprotein; TG, Triglyceride; WC, Waist circumference; MAP, Mean arterial pressure; WHR, Waist-to-hip ratio.

$* * P<0.05$

$(P=0.050)$ and $\mathrm{GC}+\mathrm{RT}$ groups $(P=0.032)$ significantly increased, and TC groups significantly decreased in the $\mathrm{RT}+\mathrm{P}(P=0.023), \mathrm{GC}+\mathrm{RT}(P=0.006)$, and GC $(P=0.041)$ (Table 3).

\section{Discussion}

As obesity and fatty liver disease have similar pathophysiologic mechanisms such as inflammation, insulin resistance, and oxidative stress, it has been hypothesized that obesity is associated with increased risk of NAFLD (24). In this respect, a study found that more than $91 \%$ of obese individuals (BMI $>30 \mathrm{~kg} / \mathrm{m}^{2}$ ) showed evidence of fatty liver (25). However, there have yet been no studies comparing the effect of RT with elastic bands and consuming GC supplement on some novel noninvasive hepatic disorder indices in obese middle-aged women.

The present clinical trial was carried out to examine the effects of $500 \mathrm{mg} / \mathrm{d}$ of GC supplementation along with resistance elastic band training during eight weeks in women with obesity. Significant reductions were also observed in serum HDL level in RT+P and GC+RT groups compared with the P group. Moreover, GC+RT had no significant impacts on serum LDL, TG, ALT, AST, GGT, 
and FBG levels as well as FSI and HSI. The GC dose used in the present study provided $250 \mathrm{mg}$ of CGA per day. This amount of CGA may be achieved by daily intake of coffee that may include 0.5 to $1.0 \mathrm{~g}$ of CGA per day (26). However, in Iranian population, especially in the region of this study, the consumption of GC and other drinks containing CGA is not common, and therefore a daily dose of $500 \mathrm{mg}$ of GC is appropriate (27). Furthermore, at baseline, both groups consumed approximately equal amounts of macronutrient composition such as fat, carbohydrates, and protein, and number of calories per day and had a similar dietary pattern.

The GC and RT treatments were not effective in reducing liver enzymes and hepatic steatosis biomarkers. The association between GC intake and hepatic steatosis biomarkers has not yet been studied. In the present study, insignificant changes in circulating liver enzymes were also observed in the experimental groups compared with placebo. However, the degree of steatosis was not measured in this study.

In contrast to the present study, previous investigations revealed that increased coffee consumption was associated with lower liver enzymes and liver-related mortality $(28,29)$. In fact, the purpose of this study was not to examine NAFLD with focus on non-invasive indices of fatty liver (FSI and HSI), which have been shown to be highly correlated with ultrasonographic fatty liver $(22,30,31)$. No improvements in noninvasive hepatic biomarkers were observed in the three studied groups throughout the present study since AST and ALT did not decrease significantly. As previously reported, of the parameters used to calculate these hepatic steatosis biomarkers, changes in BMI, waist circumference, TG, and HDL cholesterol were not significantly more marked in participants in experimental groups than in placebo groups in this study.

It has been hypothesized that these interventions might modulate FSI in a different manner. The results of the present 8-week study conducted on obese women with hepatic disorders showed that multi-interventions might not be sufficient to improve hepatic disorders. It has recently been shown that a significant improvement in bright liver score is achieved following a 6-month Mediterranean diet intervention and exercise training (32); however, fatty liver changes were not significant at the first and third months of monitoring.

It was found that decreases in FSI were not significant in experimental groups compared with placebo. There has yet been no published study directly assessing the effects of exercise training and supplement on FSI in adults. It can be speculated that exercise alone or along with GC is likely insufficient to improve FSI in all groups. The results of the present study confirmed the hypothesis that RT did not improve FSI in a superior manner compared to combined RT and GC in obese women. It seems that these non-significant decreases in FSI are dependent on body composition in obese women (33) because it has been demonstrated that the level of improvement in hepatic biomarkers of obese subjects after exercise training intervention is associated with the degree of weight loss. In addition, it has been previously shown that the beneficial effects of coffee on liver parameters might be manifested in patients with chronic liver diseases (28).

However, it is possible that significant differences between the four subgroups would have emerged if treatments were of longer duration (34). These findings are not in line with a number of studies that provided evidence in support of CGA and GC extract as an effective compound in lowering fatty liver (35-38). Shahmohammadi et al (3) were the first to show that GC supplementation significantly improved the level of AST. Recently, Tajik et al have reported in a review article that CGA is able to exert pivotal roles on hepatic steatosis (39). The discrepancy in the effects of CGA in GC between the present study and others might be explained by different methods of CGA administration. Additionally, the dose and duration used in these trials might explain some of the variations in findings compared to the present study. Consistent with previous reports (40), the present trial did not support the hypothesis that the supplementation of GC will improve hepato-metabolic complications in obese individuals. Most studies have addressed hepatic steatosis regulation during low-to-moderate aerobic training, but other kinds of training such as resistance training may be different.

\section{Limitations of the Study}

The present study had several potential limitations. First, the small size of the subjects could be considered as a limitation of the study. Second, given the ethical and practical considerations, it was not possible to conduct a repeated liver biopsy for histology analysis. Therefore, the hepatic fat content was not measured by the laboratory. Third, no ultrasonography was utilized to detect fatty liver, which was another limitation of the present study. In addition, the short duration of the study could be considered as the other limitation of this study. Further interventional studies on animals and humans are required to determine if GC is able to protect against fatty liver or not.

\section{Conclusion}

In summary, no significant decrease was found in hepatic steatosis in middle-aged obese women. Therefore, it is suggested that resistance exercises and other kinds of exercise training along with GC supplement might have the potential to improve hepatic steatosis indices in a longer duration. Additionally, higher GC dosage is suggested for future studies. 
Conflict of Interests

There is no conflict of interest to report.

\section{Ethical Approval}

The protocol of this study was also approved by the Ethics Committee of Shahrekord University (ethics committee reference number: IR-SKU.95/125).

Authors' Contributions

$\mathrm{EB}$ and $\mathrm{TJ}$ designed the study. ZT and EB supervised exercise training protocols. EB supervised laboratory exams and data collection. EB and MMG analyzed and interpreted the data. EB and ZT wrote the first draft of the manuscript. EB edited the paper. All the authors contributed to the writing of the paper. All the authors read and approved the final manuscript.

Funding/Support

There is no funding.

\section{Acknowledgments}

The authors would like to thank all the study participants. This manuscript was derived from a research project (code: 2433659, approval date: 2017-06-21) approved by Research Deputy of Shahrekord University.

\section{References}

1. Emamian $\mathrm{MH}$, Fateh $\mathrm{M}$, Hosseinpoor $\mathrm{AR}$, Alami $\mathrm{A}$, Fotouhi A. Obesity and its socioeconomic determinants in Iran. Econ Hum Biol. 2017;26:144-50. doi: 10.1016/j.ehb.2017.03.005.

2. Wang Z, Xu M, Hu Z, Shrestha UK. Prevalence of nonalcoholic fatty liver disease and its metabolic risk factors in women of different ages and body mass index. Menopause. 2015;22(6):667-73. doi: 10.1097/gme.0000000000000352.

3. Shahmohammadi HA, Hosseini SA, Hajiani E, Malehi AS, Alipour M. Effects of green coffee bean extract supplementation on patients with non-alcoholic fatty liver disease: a randomized clinical trial. Hepat Mon. 2017;17(4):e12299. doi: 10.5812/ hepatmon.45609.

4. Kahl S, Straßburger K, Nowotny B, Livingstone R, Klüppelholz $B$, Keßel K, et al. Comparison of liver fat indices for the diagnosis of hepatic steatosis and insulin resistance. PLoS One. 2014;9(4):e94059. doi: 10.1371/journal.pone.0094059.

5. Fedchuk L, Nascimbeni F, Pais R, Charlotte F, Housset C, Ratziu V. Performance and limitations of steatosis biomarkers in patients with nonalcoholic fatty liver disease. Aliment Pharmacol Ther. 2014;40(10):1209-22. doi: 10.1111/ apt.12963.

6. Zelber-Sagi S, Godos J, Salomone F. Lifestyle changes for the treatment of nonalcoholic fatty liver disease: a review of observational studies and intervention trials. Therap Adv Gastroenterol. 2016;9(3):392-407. doi: $10.1177 / 1756283 \times 16638830$.

7. Schranz N, Tomkinson G, Olds T. What is the effect of resistance training on the strength, body composition and psychosocial status of overweight and obese children and adolescents? a systematic review and meta-analysis. Sports Med. 2013;43(9):893-907. doi: 10.1007/s40279-013-0062-9.

8. Van Der Heijden GJ, Wang ZJ, Chu Z, Toffolo G, Manesso E, Sauer PJ, et al. Strength exercise improves muscle mass and hepatic insulin sensitivity in obese youth. Med Sci Sports Exerc. 2010;42(11):1973-80. doi: 10.1249/MSS.0b013e3181df16d9.

9. Hallsworth K, Fattakhova G, Hollingsworth KG, Thoma C, Moore S, Taylor R, et al. Resistance exercise reduces liver fat and its mediators in non-alcoholic fatty liver disease independent of weight loss. Gut. 2011;60(9):1278-83. doi: 10.1136/gut.2011.242073.

10. Cardoso GA, Salgado JM, Cesar Mde C, Donado-Pestana $\mathrm{CM}$. The effects of green tea consumption and resistance training on body composition and resting metabolic rate in overweight or obese women. J Med Food. 2013;16(2):120-7. doi: 10.1089/jmf.2012.0062.

11. Zelber-Sagi S, Nitzan-Kaluski D, Goldsmith R, Webb $M$, Zvibel I, Goldiner I, et al. Role of leisure-time physical activity in nonalcoholic fatty liver disease: a population-based study. Hepatology. 2008;48(6):1791-8. doi: 10.1002/hep.22525.

12. Rodriguez de Sotillo DV, Hadley M. Chlorogenic acid modifies plasma and liver concentrations of: cholesterol, triacylglycerol, and minerals in (fa/fa) Zucker rats. J Nutr Biochem. 2002;13(12):717-26. doi: 10.1016/s09552863(02)00231-0.

13. Meng S, Cao J, Feng Q, Peng J, Hu Y. Roles of chlorogenic acid on regulating glucose and lipids metabolism: a review. Evid Based Complement Alternat Med. 2013;2013:801457. doi: 10.1155/2013/801457.

14. Cho AS, Jeon SM, Kim MJ, Yeo J, Seo KI, Choi MS, et al. Chlorogenic acid exhibits anti-obesity property and improves lipid metabolism in high-fat diet-induced-obese mice. Food Chem Toxicol. 2010;48(3):937-43. doi: 10.1016/j. fct.2010.01.003.

15. Shimoda $H$, Seki $E$, Aitani M. Inhibitory effect of green coffee bean extract on fat accumulation and body weight gain in mice. BMC Complement Altern Med. 2006;6:9. doi: 10.1186/1472-6882-6-9.

16. Veluswamy SK, Babu AS, Sundar LM. Complementary role of herbal medicine and exercise in cardiovascular disease prevention and management: a review of evidence. Curr Pharm Des. 2017;23(8):1253-64. doi: 10.2174/1381612822 666161010122252.

17. Esteghamati A, Mazaheri T, Vahidi Rad M, Noshad S. Complementary and alternative medicine for the treatment of obesity: a critical review. Int J Endocrinol Metab. 2015;13(2):e19678. doi: 10.5812/ijem.19678.

18. Booth FW, Laye MJ. The future: genes, physical activity and health. Acta Physiol (Oxf). 2010;199(4):549-56. doi: 10.1111/j.1748-1716.2010.02117.x.

19. Sherwood NE, Jeffery RW. The behavioral determinants of exercise: implications for physical activity interventions. Annu Rev Nutr. 2000;20:21-44. doi: 10.1146/annurev.nutr.20.1.21.

20. Turner L, Shamseer L, Altman DG, Weeks L, Peters J, Kober T, et al. Consolidated standards of reporting trials (CONSORT) and the completeness of reporting of randomised controlled trials (RCTs) published in medical journals. Cochrane Database Syst Rev. 2012;11(11):MR000030. doi: 10.1002/14651858. MR000030.pub2.

21. Faul F, Erdfelder E, Lang AG, Buchner A. G*Power 3: a flexible statistical power analysis program for the social, behavioral, and biomedical sciences. Behav Res Methods. 2007;39(2):175-91. doi: 10.3758/bf03193146.

22. Lee JH, Kim D, Kim HJ, Lee CH, Yang JI, Kim W, et al. Hepatic steatosis index: a simple screening tool reflecting nonalcoholic fatty liver disease. Dig Liver Dis. 2010;42(7):503-8. doi: 10.1016/j.dld.2009.08.002.

23. Long MT, Pedley A, Colantonio LD, Massaro JM, Hoffmann $U$, Muntner $P$, et al. Development and validation of the Framingham steatosis index to identify persons with hepatic steatosis. Clin Gastroenterol Hepatol. 2016;14(8):1172-80.e2. doi: 10.1016/j.cgh.2016.03.034.

24. Fabbrini E, Sullivan S, Klein S. Obesity and nonalcoholic fatty liver disease: biochemical, metabolic, and clinical implications. Hepatology. 2010;51(2):679-89. doi: 10.1002/ 
hep. 23280 .

25. Amarapurkar D, Kamani P, Patel N, Gupte P, Kumar P, Agal S, et al. Prevalence of non-alcoholic fatty liver disease: population based study. Ann Hepatol. 2007;6(3):161-3.

26. Thom E. The effect of chlorogenic acid enriched coffee on glucose absorption in healthy volunteers and its effect on body mass when used long-term in overweight and obese people. J Int Med Res. 2007;35(6):900-8. doi: 10.1177/147323000703500620.

27. Gaeini Z, Bahadoran Z, Mirmiran P, Azizi F. Tea, coffee, caffeine intake and the risk of cardio-metabolic outcomes: findings from a population with low coffee and high tea consumption. Nutr Metab (Lond). 2019;16:28. doi: 10.1186/ s12986-019-0355-6.

28. Ruhl CE, Everhart JE. Coffee and caffeine consumption reduce the risk of elevated serum alanine aminotransferase activity in the United States. Gastroenterology. 2005;128(1):24-32. doi: 10.1053/j.gastro.2004.09.075.

29. Inoue $M$, Kurahashi $N$, Iwasaki $M$, Shimazu T, Tanaka $Y$, Mizokami M, et al. Effect of coffee and green tea consumption on the risk of liver cancer: cohort analysis by hepatitis virus infection status. Cancer Epidemiol Biomarkers Prev. 2009;18(6):1746-53. doi: 10.1158/1055-9965.epi-08-0923.

30. Yang BL, Wu WC, Fang KC, Wang YC, Huo TI, Huang YH, et al. External validation of fatty liver index for identifying ultrasonographic fatty liver in a large-scale cross-sectional study in Taiwan. PLoS One. 2015;10(3):e0120443. doi: 10.1371/journal.pone.0120443.

31. Cheung CL, Lam KS, Wong IC, Cheung BM. Non-invasive score identifies ultrasonography-diagnosed non-alcoholic fatty liver disease and predicts mortality in the USA. BMC Med. 2014;12:154. doi: 10.1186/s12916-014-0154-x.

32. Trovato FM, Catalano D, Martines GF, Pace P, Trovato GM. Mediterranean diet and non-alcoholic fatty liver disease: the need of extended and comprehensive interventions. Clin Nutr. 2015;34(1):86-8. doi: 10.1016/j.clnu.2014.01.018.
33. Johnson NA, Sachinwalla T, Walton DW, Smith K, Armstrong A, Thompson MW, et al. Aerobic exercise training reduces hepatic and visceral lipids in obese individuals without weight loss. Hepatology. 2009;50(4):1105-12. doi: 10.1002/ hep.23129.

34. Sigal RJ, Kenny GP, Wasserman DH, Castaneda-Sceppa C, White RD. Physical activity/exercise and type 2 diabetes: a consensus statement from the American Diabetes Association. Diabetes Care. 2006;29(6):1433-8. doi: 10.2337/dc06-9910.

35. Liang H, Yang J, Tang J, Wu C, Li H, Chen S. Optimization of dosage ratio of chlorogenic acid and gardenia glycosides in the treatment of rats with fatty liver disease induced by highfat feed. J Tradit Chin Med. 2016;36(5):683-8. doi: 10.1016/ s0254-6272(16)30090-5.

36. Ma Y, Gao M, Liu D. Chlorogenic acid improves high fat diet-induced hepatic steatosis and insulin resistance in mice. Pharm Res. 2015;32(4):1200-9. doi: 10.1007/s11095-0141526-9.

37. Bassoli BK, Cassolla P, Borba-Murad GR, Constantin J, Salgueiro-Pagadigorria CL, Bazotte RB, et al. Chlorogenic acid reduces the plasma glucose peak in the oral glucose tolerance test: effects on hepatic glucose release and glycaemia. Cell Biochem Funct. 2008;26(3):320-8. doi: 10.1002/cbf.1444.

38. Ong KW, Hsu A, Tan BK. Chlorogenic acid stimulates glucose transport in skeletal muscle via AMPK activation: a contributor to the beneficial effects of coffee on diabetes. PLoS One. 2012;7(3):e32718. doi: 10.1371/journal.pone.0032718.

39. Tajik N, Tajik M, Mack I, Enck P. The potential effects of chlorogenic acid, the main phenolic components in coffee, on health: a comprehensive review of the literature. Eur J Nutr. 2017;56(7):2215-44. doi: 10.1007/s00394-017-1379-1.

40. Mubarak A, Hodgson JM, Considine MJ, Croft KD, Matthews VB. Supplementation of a high-fat diet with chlorogenic acid is associated with insulin resistance and hepatic lipid accumulation in mice. J Agric Food Chem. 2013;61(18):43718. doi: 10.1021/jf400920x. 